\title{
Cancer Stem Cells Promote Tumor Neovascularization
}

\author{
Yi-fang Ping, Xiao-hong Yao, Shi-cang Yu, \\ Ji Ming Wang and Xiu-wu Bian \\ The Third Military Medical University \\ China
}

\section{Introduction}

Tumor growth and metastasis depend on neovascularisation, which has been recently believed promoted by cancer stem cells (CSCs), a special subpopulation of tumor cells. The cancer stem cell theory can be traced back to the first mention by Furth and Kahn in 1937, when their results revealed a single leukaemic cell capable of transmitting the systemic disease in mice [1]. However, it was not until the 1990s that CSCs were identified and wellcharacterized in acute myeloid leukaemia (AML). Among cancer cells isolated from AML patients, only a small fraction of them exhibiting the hematopoietic stem cell surface phenotype, i.e. CD34+ and CD38-, were capable of initiating leukaemia in mice similar to that of the original patient. These cells were then known as SCID leukemia-initiating cells with potentials to self-renew, proliferate and differentiate in vivo $[2,3]$. Since then, CSCs from various types of cancer such as breast cancer and malignant glioma have been well characterized, and then the existence of CSCs in solid tumors has been gradually accepted [4-10]. The studies promote a common recognition of the accurate definition for CSCs reached by an American Association for Cancer Research (AACR) workshop in 2006, that CSCs are a small subset within a cancer that constitute a reservoir of self-sustaining cells with the exclusive abilities to self-renew and to cause the heterogeneous lineages of cancer cells that comprise the tumor [11].

Investigation on CSCs provides a new insight into our understanding for tumorigenesis, recurrence and metastasis of cancer as well as development of new strategies for cancer treatment. Due to up-regulation of drug resistance and anti-apoptotic genes as well as greater DNA-repair responses, CSCs are more resistant to chemo- and/or radiotherapies than differentiated cancer cells [12-17]. Recent studies suggest that CSCs existing in the tumor are highly invasive, indicating their crucial role in invasion and metastasis of cancer [18]. Therefore, eradication of CSCs is of great importance in preventing cancer recurrence and metastasis.

The increasing awareness of neovascularization holding a master switch of tumor development and progression indicates that vascularization plays a crucial role in the stage of tumor progression [19]. It is generally thought that vascularization is initiated by microenvironmental changes such as hypoxia followed by tumor outgrowing its blood 
supply limitation. This process is further promoted by angiogenic factors derived from tumor cells and infiltrating inflammatory/immune cells into tumor tissues [20-22]. Tumor vasculatures are mainly developed through angiogenesis by sprouting from pre-existing vessels and vasculogenesis via recruitment of endothelial progenitor cells (EPCs) [23, 24]. Both of the processes are initiated and promoted by angiogenic factors [20, 22, 25] such as vascular endothelial growth factor (VEGF) and basic fibroblast growth factor (bFGF) produced by cancer cells and stromal cells [22, 26, 27]. Interestingly, cancer cells exhibit heterogeneity in their production of angiogenic factors.

CSCs have been more recently identified as initiating cells of tumor neovascularization [2833], but many doubts still challenge CSC theory. In this review, we provide the evidence for the role of CSCs in tumor vascularization and discuss the potential therapeutic significance based on the interaction between CSCs and their vascular niches.

\section{CSCs produce angiogenic factors}

CSCs play a predominant role in tumor angiogenesis through producing high levels of proangiogenic factors. Evidence from our laboratory and others has indicated that CSCs produce preferentially higher levels of angiogenic factors, for instance, VEGF and interleukin 8 (IL-8). Ponti et al identified a subpopulation of sphere-forming cells with CSC properties, named MCF-S, from an established breast carcinoma cell line MCF-7 [28]. It was found that MCF-S cells expressed higher levels of VEGF mRNA compared with MCF-7. Meanwhile, higher amounts of VEGF protein were measured in the MCF-S culture medium, indicating CSCs might possess stronger pro-angiogenic capability than differentiated tumor cells. Bao et al found that hypoxia could induce glioma stem cells to produce higher levels of angiogenic factor VEGF [29]. CSC-enriched neurospheres derived from the GL261 murine glioma cell line and rat glioma cell line C6 express more VEGF compared with adherent, CSC-low cultures [30, 31]. Compared with adherent C6 cells, sphere-forming C6 cells induced higher levels of proliferation and tubulogenesis of endothelial cells in vitro. Accordingly, xenografts derived from sphere-forming C6 cells exhibited increased microvessel density and blood perfusion and induced increased mobilization and tumor recruitment of bone marrow-derived endothelial progenitor cells (EPCs). When VEGF was blocked, all aspects of angiogenesis observed in sphere-forming C6 cells and xenografts, including microvessel density, perfusion, EPC mobilization/recruitment, and stimulation of endothelial cell activity, were reduced to levels comparable with those observed in either adherent C6 cells or their implanted tumors [31]. Furthermore, CSC-enriched CD133+ fraction derived from the U87 human glioblastoma cell line and primary human gliomas also had a significantly stronger capacity of promoting angiogenesis than the CSC-depleted CD133- fraction. Accordingly, CD133+ glioma cells generated highly vascularized tumors when implanted in mice, whereas the matched CD133 populations were rarely tumorigenic and gave rise to poorly vascularized tumors. The proangiogenic capacity of CD133+ fraction was attributable to VEGF activity [29,32]. The evidence of in vivo pro-angiogenic effects of CSCs was further proved by Oka and the colleagues [33]. Transfecting glioma stem cells with a retrovirus vector expressing VEGF promoted vascular formation and tumorassociated hemorrhage. The blood vessels adjacent to and within the tumors derived from VEGF-expressing glioma stem cells exhibited much higher density and more complexity of 
neovascularization. The newly formed vessels had functional walls and lumens when they were stained with anti-CD31 antibody and PAS histochemistry demonstrated central lumens and new basement membrane. Taken together, VEGF appears to be an important mediator for CSC contribution to tumor neovascularization.

Chemokines and their receptors are believed to be involved in CSCs-mediated production of angiogenic factors. For instance, CXCR4, a chemokine receptor that plays an important role in tumor angiogenesis, was preferentially expressed in glioma stem cells [16, 34-36]. Meanwhile, stromal derived factor-1 (SDF-1) or CXCL12, the sole ligand for CXCR4, can be detected in glioma stem cell culture medium, indicating that CXCR4 expressed by glioma stem cells can be activated in an autocrine manner. Using a rat aortic ring assay, Salmaggi and the colleagues found glioma stem cells induced apparently longer and thinner neovessels compared with control group. They further documented high expression of CXCR4 and release of CXCL12 by glioma stem cells might be the underlying mechanism [34]. In our recent studies, we also found that CD133+ glioma stem cells had significantly higher CXCR4 mRNA and protein expression levels, as well as higher chemotactic response to its ligand CXCL12 as compared to CD133 negative cells [37]. In addition to chemokine receptor CXCR4, formylpeptide receptor (FPR), a classic chemoattractant receptor, was also found to induce VEGF production by glioma stem cells [32]. This G-protein coupled receptor mediates neutrophils to participate in inflammation, and we previously found its promotion of tumor growth and invasion through its activation by binding its stimulator from necrotic tumor cells. We recently reported this receptor expressed on glioma stem cells was functional and its activation promotes stem cells production of angiogenic factors such as VEGF and IL-8/CXCL8, resulting in initiation of angiogenesis. When transplanting human CSCs into nude mice, the CSCs produced in situ angiogenic factors and generated a higher density of microvessels to promote tumor growth. These results strongly suggest that chemoattractants and their receptors, at least in part, are among the major signals to promote CSC-mediated tumor angiogenesis by stimulating VEGF production.

Although a greater contribution of CSCs to tumor angiogenesis than their differentiated counterparts within a tumor has been supported by many studies, contradictory phenomenons have also been observed. Salmaggi et al found non-sphere-forming cells from GBM could induce more vessels than glioma stem cells using the aortic ring assay. They observed that the pro-angiogenic capacity varied among different passages of glioma stem cells. Pro-angiogenic ability of glioma stem cells increased after serial passages in culture concomitant with elevated VEGF and CXCL12 production [34]. Consequently, VEGF mRNA was increased in the secondary tumor spheres acquired from primary tumorospheres of xenografts [34]. Recently, Sakariassen et al observed angiogenesis-dependent and angiogenesis-independent patterns in glioma stem cell-derived xenografts [38]. Great differences were seen in gene expression profiles and signaling pathways between the glioma stem cells with two different tumor generation patterns. These results indicate that CSCs are actually heterogeneous in their contribution to neovascularization. Further studies are still needed to elucidate the exact subclones preferentially contributing to tumor angiogenesis for more effective targeting to angiogenesis-initiating stem cells.

\section{CSCs transdifferentiate into endothelial cells}

Endothelial cells (ECs) not only interact with cancer cells through aberrant growth factors, but also share genetic abnormality with cancer cells, which might suggest a link in their 
common origin [39-41]. Streubel et al investigated 27 cases of lymphoma and found $15 \%$ to $85 \%$ of the microvascular ECs harbored the same lymphoma-specific genetic aberrations. In vitro assays also showed that the ECs isolated from primary human lymphoma presented the lymphoma-specific genetic aberrations [39]. In multiple myeloma patients with the $13 q 14$ deletion, a significant proportion of circulating ECs carried the same chromosome aberration as the neoplastic plasma cells, and presented the same immunoglobulin gene rearrangement as multiple myeloma plasma cells. In addition, most circulating ECs presented EPC features as they expressed CD133, a marker gradually lost during endothelial differentiation and absent on mature ECs [40]. Renal tumor-derived ECs but not normal ECs expressed paired-box 2 (Pax2) proteins and mRNA, which were restricted to the developing kidney in the embryo [41]. These results suggest that cancer cells and ECs might derive from common multipotent progenitor cells, or possibly CSCs.

More evidence supports that CSCs might generate or transdifferentiate into ECs for neovascularization. Pezzolo et al investigated the origin of the microvascular ECs in MYCNamplified nephroblastoma and found that $20 \%-78 \%$ of the ECs identified by CD105 expression exhibited amplification of the oncogene MYCN, the tumor marker of this tumor at stage 3 and 4 . This finding strongly implicates the possible cancer cell origin of ECs in MYCN amplification nephroblastoma. Furthermore, microvessels formed by the ECs were functional because they contained erythrocytes and were covered with a layer of pericytes. They further studied a cell line HTLA-230 from human stage 4 nephroblastoma with MYCN amplification and injected the cells into immunodeficient mice to investigate the origin of ECs in the xenografts. It was found that the xenografts contained approximately $80 \%$ of human ECs and 20\% murine ECs, suggesting the nephroblastoma cells directly transdifferentiating to tumor ECs $[42,43]$.

More direct evidence of the potential transdifferentiation of CSCs to ECs has been reported in recent years. In a study with the injecting fluorescence-labeled human cutaneous metastatic melanoma cells into the ischemic hind limbs of nude mice, it was found that after five days, the vessels consisted of human melanoma-derived cells adjacent to and overlapping with mouse ECs in a linear arrangement were formed and provided blood for the ischemic limbs [44]. A CD133+ cell population, which is negative for the endothelial marker CD34, but positive for the renal embryonic marker Pax-2, derived from human renal carcinomas was also able to differentiate into ECs. When injected subcutaneously in SCID mice, they formed functional vessels which integrated with the mouse vasculature. Among the tumor vasculature, vessels of human origin accounted for $85 \%$ and were mainly located within the tumors [45]. Kusumbe et al isolated a non-tumorigenic CD133+ population in ovarian cancer and termed them as endothelial stem cells (EnSCs) based on their capacity of differentiating into ECs. A unique feature of these EnSCs is the continual expression of the surface molecule CD44 at all the steps of the hierarchy [46]. In the two reports, the authors did not detect the cellular karyotypes, thus we cannot know whether these cells are normal or abnormal in their phenotype. However, the expression of Pax-2 or CD44 suggested that they are not hematopoietic cells or endothelial cells. As they were isolated from tumors, it can be hypothesized that this CD133+ population might be a committed lineage that derived from CSCs and could differentiate into ECs but not tumor cells. This was confirmed by Shen and his colleagues who found precancerous stem cells (pCSCs), representing the early stage of developing CSCs, can not only initiate tumors but also generate most of the tumor vasculature [47, 48]. More recently, Bussolati and the colleagues isolated and cloned a 
population of breast CSCs, which were able to differentiate into the endothelial lineage acquiring endothelial markers and the ability to organize in Matrigel into capillary-like structures when cultured in the presence of VEGF. The capacity of in vivo endothelial differentiation was proven by vessels of human origin in the transplanted tumors, formed by these cells [49]. Evidence from the studies of CSCs in human renal carcinomas and ovarian cancers also confirmed the capacity of CSCs to transdifferentiate into endothelial cells. CD105+ tumor-initiating cells isolated from human renal carcinomas acquired an endothelial phenotype when cultured in endothelial differentiating medium containing VEGF and generated ECs of human origin in the central of SCID xenografts [50]. Ovarian cancer cells with stem-like properties can also transdifferentiate into ECs both in intro and in vivo. Interestingly, this transdifferentiating process was shown to be VEGF-independent, but IKK $\beta$-dependent [51], suggesting either VEGF-dependent or VEGF-independent mechanisms are involved in the trans-endothelial differentiation of CSCs.

\section{CSCs contribute to vasculogenic mimicry}

It is a widely-accepted paradigm that tumor vasculature is mostly composed of nonmalignant endothelial cells originating from pre-existing blood vessels sprouting into tumor mass and recruitment of circulating endothelial progenitor cells (EPCs) mediated by angiogenic growth factors produced by host or tumor cells [52]. However, classical patterns of angiogenesis and vasculogenesis have been challenged by clinical investigation of tumor tissues because tumor vasculature can also be formed by vasculogenic mimicry (VM) [53].

$\mathrm{VM}$ is a structure through which tumor tissues nourish themselves, mimicking the pattern of embryonic vascular network. Tumor cells with high degree of differentiation plasticity may contribute to the de novo formation of tumor cell-lined blood channels [54]. These extracellular matrix-rich vasculogenic tumor cell networks were shown to conduct fluid. An interesting observation was that VM was most frequently observed in the boundary regions between the tumor and surrounding normal tissues [55]. Thus, VM may also play a role in tumor invasion by supplying immediate nutrition. Furthermore, angiogenesis inhibitors abrogate new vessels formed by human vascular endothelial cells in vitro, while under the same conditions did not affect tumor cell tuber network formation, and even induced the formation of VM as an escape route by tumor tissue for progressive growth [56]. Therefore, VM might represent an important survival mechanism contributing to the failure of current antiangiogenic therapy aimed to fully deprive tumors of blood supply [57]. Despite its clinical importance, the cellular and molecular events underlying the formation of VM are not well understood. Recent discovery of cancer stem cells (CSCs), with the capability of self-renewal and multi-potency of differentiation, has stimulated great interest in redefining tumor initiation and progression [58]. However, whether CSC theory can be applied to the formation of tumor cell-associated vasculogenesis, especially in respect to $\mathrm{VM}$, remains unclear. Based on the present findings that most vessels in tumor may be originated from tumor cell themselves through the process of vasculogenesis [59], as well as that CSCs were able to serve as precursors of tumor stromal components such as tumor vasculogenic stem/progenitor cells (TVPCs) regulated by signals from microenvironment/niche surrounding these cells [60], it is plausible that CSC compartment of a tumor may be involved in VM formation, by differentiating/transdifferentiating into endothelial-like cells. Such a potential function of CSCs might represent one of the 
mechanisms by which CSCs initiate neoplastic formation and promote tumor progression [61]. In this review, we will focus on the possible role of CSCs in VM formation and how the niche surrounding CSCs may affect VM formation.

\subsection{Current understanding of tumor VM}

In 1999, Maniotis et al. first described VM in aggressive melanoma with tumor cells expressing endothelial phenotype pasted on the surface of the basement membrane in tubular structure [62]. VM in the tumor mass is connected with host vessels for blood supply. Periodic acid-Schiff (PAS) staining is commonly utilized to identify VM. PASpositive channels were lined externally by tumor cells, lacking an inner lining of endothelial cells [63]. Although the functionality and contribution of VM channels to circulation were criticized initially, Frenkel et al. [64] demonstrated that blood circulated in VM tube with laser scanning confocal angiography in a patient with a choroidal melanoma. Therefore, VM is a new pattern that provides tumor mass with nutrition independent of conventional angiogenesis and vasculogenesis. Zhang et al. [65] proposed three-stage blood supply patterns in tumor including VM, mosaic vessels (MV) and endothelium-dependent vessels, in which all three patterns provide blood supply. The model proposes that VM is the dominant blood supply pattern in the early stage characterized by rapid tumor growth. Consequently, to maintain expansion of tumor mass, endothelial cells differentiate and proliferate, and the mosaic vessels appeared as a transitional pattern. Endotheliumdependent vessels then replace VM and mosaic vessels to become a major pattern of blood supply in the late stage of tumor growth. Thus, VM may be the main source of blood supply at the early stage of rapid tumor growth, when endothelium-dependent vessels, which require the sprouting and recruitment of endothelial cells, are insufficient to sustain aggressive tumor growth. Based on PAS staining, VM are divided into seven categories: straight channels, parallel straight pattern, parallel straight pattern with cross link, arcs (not closed), arcs with branching, closed loops, and networks [66].

$\mathrm{VM}$ has been detected in melanoma, breast carcinoma, prostate carcinoma, ovarian carcinoma, astrocytoma, and Ewing sarcoma, etc.[67-70]. Microarray analysis indicates that VM-positive tumor cells of aggressive melanoma expresses elevated levels of genes associated with undifferentiated embryonic-like phenotype [54]. Intra-peritoneally implantation of human ovarian cancer cell line SKOV3ip showed that the cells, expressing CD31 and Factor VIII of vascular epithelial markers, had plasticity to engage in VM formation in vivo [71]. These findings suggest that the plasticity of cancer cells enable them to mimic the activities of endothelial cells and participate in the process of VM formation. Recent findings of "plastic" endothelial-like phenotype of tumor cells provide additional evidence for the role of tumor cells in VM formation.

There are striking parallels between tumor cells and stem cells: tumors and normal tissue are comprised of phenotypically heterogeneous cell populations, and many characteristics of stem cells, for example, stem cell plasticity, which is also pertinent to tumor growth [72]. Cellular plasticity in stem cells may facilitate the formation of primary vascular network during embryonic development. Mesodermal progenitor cells differentiate in situ into endothelial cells that are organized into a primitive network to supply nutrition for the developing early embryo [73]. The subsequent remodeling of vascular network into more complex vasculature appears through the process of angiogenesis. These processes are 
similar to the formation of tumor vasculature and the plasticity of tumor cells may be important for the formation of VM.

\subsection{Differentiation plasticity of CSCs and VM formation}

CSCs are functionally defined by their capacity to regenerate tumors in xenograft mouse models [74, 75]. Similar to normal stem cells, CSCs can reproduce the heterogeneous phenotype of the parental cancer from which they are derived in transplantation, reflecting the multipotent differentiation capacity of CSCs. Plasticity defines the capacity of stem cells to differentiate or transdifferentiate into many cell types [76]. During development, multilineage differentiation plasticity is one of the characteristics of embryonic stem cells (ESC) [77]. CSCs are characterized by their stem/progenitor properties: self-renewal and the capability of differentiation into heterogeneous tumor cell populations [11]. Therefore, the differentiation plasticity of normal stem cells is also a similar property of CSCs. Bian et al. proposed a concept of CSC plasticity (CSCP) in which CSCs possess inducible and reversible properties in self-renewal, multipotent differentiation and invasion. For CSCs, differentiation plasticity refers to the ability of tumor cells to give rise to phenotypically diverse populations including non-tumorigenic cancer cells and stromal cells. In fact, aggressive melanoma cells forming VM appear to express genes relevant to multiple cellular phenotypes and stem cells including epithelial, endothelial, muscle, neuronal, and other cell types. The multipotent, plastic, and embryonic-like phenotype of these melanoma cells has also been considered as a defined property of putative malignant melanoma stem cells (MMSCs) [78]. Therefore, melanoma stem cells possess the differentiation plasticity (transdifferentiation) and this property may play a critical role in VM. Recently, a transdifferentiative capability has been demonstrated for bone marrow macrophages, which form VM in multiple myeloma. Thus, at least in melanoma, VM channel was believed to be due to the transdifferentiation of MMSC subset inside the aggressive tumor. In a study of breast cancer, CSCs in endothelial differentiating medium were capable of differentiating into endothelial cells, which formed both vessels and tumor [79]. It is conceivable that CSCs/tumor initiating stem cells of solid tumor have the competence of differentiation plasticity, which further supports the hypothesis that CSCs/tumor initiating stem cells possess the properties of normal stem cells important for tumor growth and vascularization. Evidence for direct involvement of tumor cells in VM was also obtained in human neuroblastoma (NB) [59]. Microvessels formed by MYCN-amplified NB tumor cells displayed an open lumen and consistently contained RBCs, indicating that these vessels were functional. Moreover, these tumor cell-derived vascular endothelial-like cells were different from normal endothelial cells in phenotype and function [59]. Although the study only tested MYNC-amplified tumor cells, it is possible that formation of tumor-derived endothelial cells is a characteristic feature of a subset of cells in neuroblastoma. In addition to neuroblastoma, tumor-associated endothelial microvessels are also found in human B-cell lymphomas and multiple myeloma [80]. It is also hypothesized that precancerous stem cells (pCSCs) representing the early stage of developing CSCs may serve as tumor vasculogenic progenitor cells (TVPCs) capable of differentiating into tumor vasculogenic endothelial cells [60]. Based on observations in animal models as well as human tumor xenografts, a model for pCSC or CSC participation in tumor vasculature formation was proposed, in which firstly, CSCs and their progenies aggregate to form a mass in tumorigenic 
microenvironment; secondly, with the extension of aggregates, a CSC subset with properties of tumor vasculogenic endothelial cells differentiate/transdifferentiate and line up to form branching lumens and tubes, resembling vascular network; and finally, the tubes extend and elongate, and the vasculature merges with host vessels from sprouting of pre-existing blood vessels and recruitment of circulating endothelial progenitor cells surrounding tumor mass. This model emphasizes the intrinsic property of CSCs in tumor vasculogenesis, and explains why most anti-angiogenic clinical trials fail to completely eradicate tumor, because the drugs tested may be effective on normal endothelial cells but not endothelial-like cells derived from CSCs [81]. Our recent studies also observed that glioma stem cells (GSCs), isolated from primary glioma sample [82] and a human glioblastoma cell line U87 [83], are capable of multipotent differentiation. In stem cell medium, such GSCs form spheroids, and in differentiation conditions they form tumor masses that contain fissure and branching lumen as revealed by electron microscope. These novel findings support the premise that $\mathrm{VM}$ positive tumor cells possess a multipotent phenotype and such cells with embryonic stem cell-like properties should be considered as antiangiogenic therapeutics.

\subsection{Microenvironmental niche as a regulator of VM formation}

The vasculogenesis and/or angiogenesis, which are necessary for tumor development and progression, involve the interaction of tumor and other cell types in the microenvironment or niche [84]. A pertinent role of the microenvironment in VM formation has been demonstrated in melanoma [85]. Collagen matrices preconditioned by aggressive melanoma cells capable of forming VM primed the lesser aggressive melanoma cells, which are initially unable to form VM, to express vasculogenic genes and to form $\mathrm{VM}$ in vitro. These observations illustrate the remarkable influence of microenvironment on the phenotype of tumor cells and provide a new perspective for the formation of VM, in which factors secreted by tumor cells or other niche components play a critical role in cancer cell plasticity, including dedifferentiation and transdifferentiation. In addition, the microenvironmental niche has been demonstrated to support normal stem cells in early co-culture and transplantation studies [86]. One of the mechanisms by which microenvironmental niche determines normal stem cell fate is the control of symmetric (producing two identical daughter cells) versus asymmetric (producing one identical and one differentiated cell) division [87]. Cancer stem cells, like normal stem cells, also depend on interaction with physiologically differentiated cell types or on non-tumorigenic cancer cell populations in the same tumor microenvironment to sustain their features and destiny [88]. Tumor environment creates a niche favoring the survival, proliferation, and differentiation of CSCs. CSCs utilize a specialized microenvironment/niche termed tumor stroma, consisted of a combination of different cell lineages, i.e. epithelial, vascular, fat, glial, fibroblast, and immune cells along with extracellular matrix, enzymes, and other secreted molecules produced by these cells [89]. It has been demonstrated that endothelial cells surrounding CSCs appear to directly generate specific microvasculature niche and/or secrete factors that promote the formation and/or maintenance of brain CSCs [90]. Critical signaling molecules, such as bone morphogenic proteins (BMPs) derived from the niche that govern embryonic vascular development, have been linked to melanoma celldriven vasculogenesis, i.e. VM [94]. In human glioblastomas, BMP4-BMPR1a signaling pathway regulates the differentiation and proliferation of CSC population [92,93]. Based 
on these findings, it is plausible that the niche surrounding CSCs controls the differentiation plasticity of CSCs, which is responsible for tumor vasculogenesis including VM formation.

In addition to being conditioned by niche components, CSCs may also reciprocally influence the niche through secretion of autocrine and/or paracrine factors or through direct cell-cell contact to benefit the maintenance of their stemness including self-renewal, multipotent differentiation, and tumor-initiation. We and others have suggested that CSCs from U87 cell line and primary human brain tumors secrete higher levels of endothelial growth factor (VEGF) than their non-tumorigenic counterpart cells that promoted the formation of tumor blood vessels [94, 29]. In breast cancer model, VEGF induces CSCs to express endothelial markers in vitro and incorporate in tumor vasculature in vivo [79]. Accumulating evidence shows in addition to vascular endothelial (VE)-cadherin, laminin $5 \gamma 2$ chain, and VEGF receptor (R)-2, angiogenic factors, including VEGF, angiogenin-1, and ephrinA1, also play a critical role in the formation of VM by tumor cells [95]. In healthy individuals, stimulation by VEGF, cells of the monocyte lineage (another mesodermal-derived cell) display an endothelial phenotype and form a functional capillary-like mesh permeable by blood cells, recapitulating embryonic vasculogenesis. VEGF also stimulated macrophages of a patient with active multiple myeloma to undergo phenotypic and functional adaptation, expressing markers of endothelial cells, i.e. VE-cadherin, VEGFR-2, and FVIII-RA, retained their own CD14 and CD68 markers, and these cells can form vessel-like structures on the Matrigel surface. Therefore, VEGF can induce macrophages to transdiferentiate into endothelial-like cells to form VM, which functionally, phenotypically and morphologically are similar to endothelial cells, yet maintain the expression of macrophage markers. Thus, VEGF in the niche, which may be derived mainly from CSCs, directly influences the phenotype of CSCs and promotes CSCs-associated VM formation.

There are three factors determining the formation of VM channel: the plasticity of VMassociated tumor cells, remodeling of extracellular matrix, and the connection of VM with host microcirculation [96]. The remodeling of extracellular matrix provides the space needed for VM and is regulated by matrix metalloproteinases (MMP) [97]. Matrix MMP-9 and MMP-2 play a critical role during the formation of VM in aggressive melanoma. Our recent study showed that the expression of MMP-9 and MMP-2 is up-regulated in glioma stem cells (GSCs) derived from U87 cell line [98]. The formation of VM also involves migration of VM-derived tumor cells. We observed that migration associated molecules, including two G-protein coupled chemoattractant receptors formylpeptide receptor (FPR) and CXC chemokine receptor-4 (CXCR4) were over-expressed in GSCs isolated from human glioblastoma and U87 cell line [84, 37]. FPR and CXCR4 expressed on GSCs, when activated by corresponding agonists, mediate directional migration, calcium mobilization, and production of VEGF by GSCs. Our recent observations further suggest that activation of CXCR4 on GSCs elicits phosphoinositide 3-kinase (PI3K) pathway which is an important regulator of VM through MMP-2 [99]. The relationship between CSCs and VM formation through stimulatory signals in the niche is important for differentiation plasticity of CSCs. Based on the existing observations, it is conceivable that CSCs take part in the VM formation through autocrine and/or paracrine manner thereby establishing a vessel niche suitable to protect and nourish CSCs. Therefore, VM-targeted therapies should be a new strategy aimed at eliminating CSCs. 


\subsection{VM-targeted therapeutic strategy: new perspectives}

CSCs are considered as the root of tumor initiation, metastasis, and reoccurrence. If CSCs are proven to be critical for VM formation, there will be significant implications in the design of novel anti-tumor therapies. As discussed earlier, VM is the dominant blood supply pattern in the early stage of tumor formation and CSCs are capable of differentiating/transdifferentiating and lining up to form branching lumens and tubes, a process resembling the formation of VM. Traditional anti-angiogenesis drugs, such as angiostatin and endostatin, which target normal endothelial cells, have little effect on VM due to the absence of normal endothelial cells [100]. In contrast, VEGF-specific inhibitor Bevacizumab can conspicuously decrease the number of self-renewing cancer cells from orthotopic models of medulloblastoma and glioma, resulting in tumor growth arrest. Direct evidence was obtained from aggressive melanoma in that LY294002, a specific inhibitor of PI3K, inhibited the ability of undifferentiated embryonic melanoma cells to engage in VM on three-dimensional type I collagen matrices [100]. Furthermore, the unique structure of VM channels, in which tumor cell line up the inner surface, directly exposes tumor cells to blood vessel and facilitates the metastasis of tumor cells. VM frequently is seen in the regions between the tumor and surrounding normal tissues, and its appearance in tumor is associated with poor prognosis in clinical patients. Therefore, VM-targeted therapies may destroy the niche that maintains CSCs, block the metastasis passage of tumor cells, and reduce the recurrence of cancer.

\section{Conclusion}

Based on these findings, we conclude that CSCs might initiate and promote neovascularization at the early stage of tumor tumorigenesis and progression. There are at least three potential mechanisms involved in this process: (1) CSCs induce neovascularization through secreting VEGF, which is further induced by hypoxia or activation of chemokine receptors; (2) CSCs might participate in angiogenesis through transdifferentiating into endothelial cells and/or endothelial progenitor cells; (3) CSCs could generate cells that form vasculogenic mimicry and provide nutrition and oxygen directly to the tumor mass (Figure 1). On the contrary, the tumor vasculature nourishes CSCs and maintains their survival and characteristics of "stemness".

Cancer stem cell hypothesis requires elimination of CSCs for more effective treatment of cancer. If CSCs exclusively generate heterogeneous tumor cells, elimination of these cells will result in arrested tumor growth and eventual eradication. The fact that CSCs contribute greatly to tumor neovascularization indicates that restraint of CSCs would impair tumor vessels. On the other hand, vascular niches support self-renewal, proliferation and differentiation of CSCs, and protect CSCs from chemo- and radiotherapies [90, 101, 102], suggesting the necessity to interfere or deplete vascular niches of CSCs. Anti-angiogenic drugs indeed reduced markedly the MVD in xenografts and arrested tumor growth [103, 104]. Thus, a combination of targeting CSCs and their vascular niche will provide more effective therapy for tumor treatment. Furthermore, differentiation induction strategy targeting the poor-differentiated CSCs may also facilitate cancer treatment [105]. However, there is a long way to go for developing the methods targeting CSCs and their vascular niche to treat cancers. 

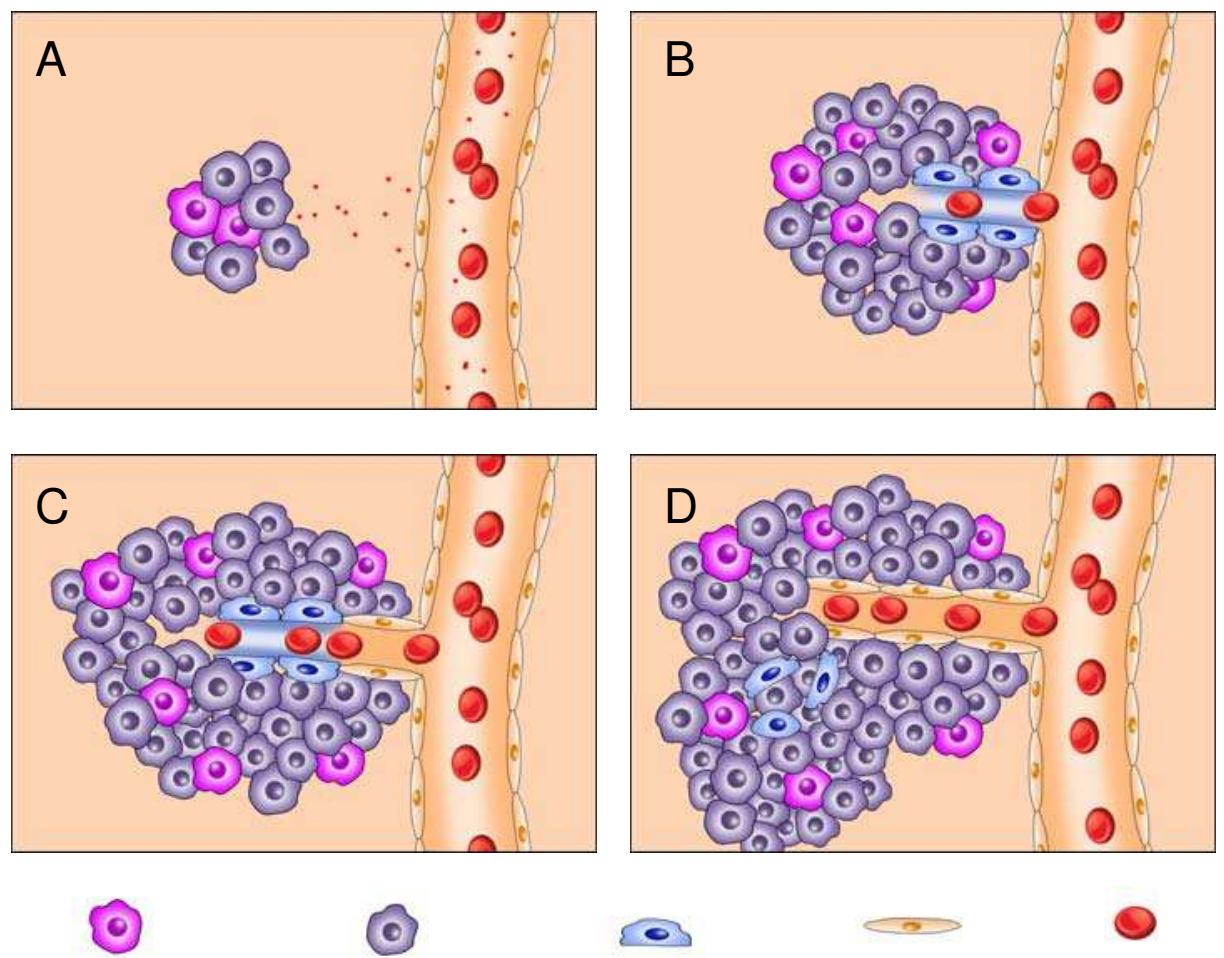

\section{Cancer stem cell Cancer cell VM-forming cell Endothelial cell Erythrocyte}

Fig. 1. Proposed mechanism of cancer stem cells (CSCs) in tumor neovascularization. CSCs self-renew and generate cancer cells (A) as well as VM-forming cells (B). The VM-forming cells can form functional lumens, incorporating with the endothelial cells either from transdifferentiation of CSCs or sprouting of endothelial cells from pre-existing vessels (known as angiogenesis), provide blood and nutrition for the tumor mass (C and D). Furthermore, proangiogenic factors produced by CSCs and cancer cells promote recruitment of circulating EPCs to the tumor tissue and integration into tumor vessels, forming new microvessels known as vasculogenesis.

\section{References}

Furth, J., \& Kahn, M. (1937). The transmission of leukaemia of mice with a single cell. Am J Cancer, 31, 276-282.

Lapidot, T., Sirard, C., Vormoor, J., Murdoch, B., Hoang, T., Caceres-Cortes, J., et al. (1994). A cell initiating human acute myeloid leukaemia after transplantation into SCID mice. Nature, 367(6464), 645-648.

Bonnet, D., \& Dick, J.E. (1997). Human acute myeloid leukaemia is organized as a hierarchy that originates from a primitive hematopoietic cell. Nat Med, 3(7), 730-737. 
Al-Hajj, M., Wicha, M.S., Benito-Hernandez, A., Morrison, S.J., \& Clarke, M.F. (2003). Prospective identification of tumorigenic breast cancer cells. Proc Natl Acad Sci USA, 100(7), 3983-3988.

Li, C., Heidt, D.G., Dalerba, P., Burant, C.F., Zhang, L., Adsay, V., et al. (2007). Identification of pancreatic cancer stem cells. Cancer Res, 67(3), 1030-1037.

Fang, D., Nguyen, T.K., Leishear, K., Finko, R., Kulp, A.N., Hotz, S., et al. (2005). A tumorigenic subpopulation with stem cell properties in melanomas. Cancer Res, 65(20), 9328-9337.

Collins, A.T., Berry, P.A., Hyde, C., Stower, M.J., \& Maitland, N.J. (2005). Prospective identification of tumorigenic prostate cancer stem cells. Cancer Res, 65(23), 1094610951.

Prince, M.E., Sivanandan, R., Kaczorowski, A., Wolf, G.T., Kaplan, M.J., Dalerba, P., et al. (2007). Identification of a subpopulation of cells with cancer stem cell properties in head and neck squamous cell carcinoma. Proc Natl Acad Sci USA, 104(3), 973-978.

Dalerba, P., Dylla, S.J., Park, I.K., Liu, R., Wang, X., Cho, R.W., et al. (2007). Phenotypic characterization of human colorectal cancer stem cells. Proc Natl Acad Sci USA, 104(24), 10158-10163.

O'Brien, C.A., Pollett, A., Gallinger, S., \& Dick, J.E. (2007). A human colon cancer cell capable of initiating tumour growth in immunodeficient mice. Nature, 445(7123), 106-110.

Clarke, M.F., Dick, J.E., Dirks, P.B., Eaves, C.J., Jamieson, C.H., Jones, D.L., et al. (2006). Cancer stem cells-perspectives on current status and future directions: AACR workshop on cancer stem cells. Cancer Res, 66 (19), 9339-9344.

Dean, M., Fojo, T., \& Bates, S. (2005). Tumour stem cells and drug resistance. Nat Rev Cancer, 5(4), 275-284.

Chalmersa, A.J. (2007). Radioresistant glioma stem cells-therapeutic obstacle or promising target? DNA Repair, 6(9), 1391-1394.

Eramo, A., Ricci-Vitiani, R., Zeuner, A., Pallini, R., Lotti, F., Sette, G., et al. (2006). Chemotherapy resistance of glioblastoma stem cells. Cell Death Differ, 13(7), 12381241.

Hirschmann-Jax, C., Foster, A.E., Wulf, G.G., Nuchtern, J.G., Jax, T.W., Gobel, U., et al. (2004). A distinct "side population" of cells with high drug efflux capacity in human tumor cells. Proc Natl Acad Sci USA, 101(39), 14228-14233.

Liu, G., Yuan, X., Zeng, Z., Tunici, P., Ng, H., Abdulkadir, I.R., et al. (2006). Analysis of gene expression and chemoresistance of CD133+ cancer stem cells in glioblastoma. Mole Cancer, 5, 67.

Bao, S., Wu, Q., McLendon, R.E., Hao, Y., Shi, Q., Hjelmeland, A.B., et al. (2006). Glioma stem cells promote radioresistance by preferential activation of the DNA damage response. Nature, 444(7120), 756-760.

Sheridan, C., Kishimoto, H., Fuchs, R.K., Mehrotra, S., Bhat-Nakshatri, P., Turner, CH., et al. (2006). CD44+/CD24- breast cancer cells exhibit enhanced invasive properties: an early step necessary for metastasis. Breast Cancer Res, 8(5), R59. 
Narazaki, M., \& Tosato G. (2006). Tumor cell populations differ in angiogenic activity: a model system for spontaneous angiogenic switch can tell us why. J Natl Cancer Inst, 98(5), 294-295.

Hanahan, D., \& Folkman, J. (1996). Patterns and emerging mechanisms of the angiogenic switch during tumorigenesis. Cell, 86(3), 353-364.

Greenblatt. M., \& Shubik. P. (1968). Tumor angiogenesis: transfilter diffusion studies in the hamster by the transparent chamber technique. J Natl Cancer Inst, 41(1), 111-124.

Folkman, J., \& Klagsbrun. M. (1987). Angiogenic factors. Science, 235 (4787), 442-447.

Fischer, I., Gagner, J.P., Law, M., Newcomb, E.W., \& Zagzag, D. (2005). Angiogenesis in gliomas: biology and molecular pathophysiology. Brain pathol, 15(4), 297-310.

Komarovaa, N.L., \& Mironov, V. (2005). On the role of endothelial progenitor cells in tumor neovascularization. J Theor Biol, 235 (3), 338-349.

Bian, X.W., Chen, J.H., Jiang, X.F., Bai, J.S., Wang, Q.L., \& Zhang, X. (2004). Angiogenesis as an immunopharmacologic target in inflammation and cancer. Int Immunopharmacol, 4(12), 1537-1547.

Gilad, A.A., Israely, T., Dafni, H., Meir, G., Cohen, B., \& Neeman, M. (2005). Functional and molecular mapping of uncoupling between vascular permeability and loss of vascular maturation in ovarian carcinoma xenografts: the role of stroma cells in tumor angiogenesis. Int J Cancer, 117(2), 202-211.

Saarinen, N.M., Abrahamsson, A., \& Dabrosin, C. (2010). Estrogen-induced angiogenic factors derived from stromal and cancer cells are differently regulated by enterolactone and genistein in human breast cancer in vivo. Int J Cancer, 127(3), 737-745

Ponti, D., Costa, A., Zaffaroni, N., Pratesi, G., Petrangolini, G., Coradini, D., et al. (2005). Isolation and in vitro propagation of tumorigenic breast cancer cells with stem/progenitor cell properties. Cancer Res, 65(13), 5506-5511.

Bao, S., Wu, Q., Sathornsumetee, S., Hao, Y., Li, Z., Hjelmeland, A.B., et al. (2006). Stem celllike glioma cells promote tumor angiogenesis through vascular endothelial growth factor. Cancer Res, 66(16), 7843-7848.

Pellegatta, S., Poliani, P.L., Corno, D., Menghi, F., Ghielmetti, F., Suarez-Merino, B., et al. (2006). Neurospheres enriched in cancer stem-like cells are highly effective in eliciting a dendritic cell-mediated immune response against malignant gliomas. Cancer Res, 66(21), 10247-10252.

Folkins, C., Shaked, Y., Man, S., Tang, T., Lee, C.R., Zhu, Z., et al. (2009). Glioma tumor stem cell-like cells promote tumor angiogenesis and vasculogenesis via vascular endothelial growth factor and stromal-derived factor 1. Cancer Res, 69(18), 7243-7251.

Yao, X.H., Ping, Y.F., Chen, J.H., Xu, C.P., Chen, D.L., Zhang, R., et al. (2008). Glioblastoma stem cells produce vascular endothelial growth factor by activation of a G-protein coupled formlpeptide receptor FPR. J Pathol, 215(4), 369-376.

Oka, N., Soeda, A., Inagaki, A., Onodera, M., Maruyama, H., Hara, A., et al. (2007). VEGF promotes tumorigenesis and angiogenesis or human glioblastoma stem cells. Biochem Biophys Res Commun, 360(3), 553-559.

Salmaggi, A., Bolardi, A., Gelati, M., Russo, A., Calatozzolo, C., Ciusani, E., et al. (2006). Glioblastoma-derived tumorospheres identify a population of tumor stem-like cells 
with angiogenic potential and enhanced multidrug resistance phenotype. Glia, 54(8), 850-860.

Ehtesham, M., Mapara, K.Y., Stevenson, C.B., \& Thompson, R.C. (2009). CXCR4 mediates the proliferation of glioblastoma progenitor cells. Cancer Lett, 274(2), 305-312.

Krohn, A., Song, Y.H., Muehlberg, F., Droll, L., Beckmann, C., \& Alt, E. (2009).CXCR4 receptor positive spheroid forming cells are responsible for tumor invasion in vitro. Cancer Lett, 280(1), 65-71.

Ping, Y.F., Yao, X.H., Bian, X.W., Chen, J.H., Zhang, R., Yi, L., et al. (2007). Activation of CXCR4 in human glioma stem cells promotes tumor angiogenesis. Zhonghua Bing Li Xue Za Zhi. 36(3),179-183.

Sakariassen, P., Prestegarden, L., Wang, J., Skaftnesmo, K.O., Mahesparan, R., Molthoff, C., et al. (2006). Angiogenesis-independent tumor growth mediated by stem-like cancer cells. Proc Natl Acad Sci USA, 103(44), 16466-16471.

Streubel, B., Chott, A., Huber, D., Exner, M., Jager, U., Wagner, O., et al. (2004). Lymphomaspecific genetic aberrations in microvascular endothelial cells in B-cell lymphomas. N Engl J Med, 351(3), 250-259.

Rigolin, G.M., Fraulini, C., Ciccone, M., Mauro, E., Bugli, A.M., De Angeli, C., et al. (2006). Neoplastic circulating endothelial cells in multiple myeloma with 13q14 deletion. Blood, 107(6), 2531- 2535.

Fonsato, V., Buttiglieri, S., Deregibus, M.C., Puntorieri, V., Bussolati, B., \& Camussi, G. (2006). Expression of Pax2 in human renal tumor-derived endothelial cells sustains apoptosis resistance and angiogenesis. Am J Pathol,168(2),706-713.

Pezzolo, A., Parodi, F., Corrias, M.V., Cinti, R., Gambini, C., \& Pistoia, V. (2007).Tumor origin of endothelial cells in human neuroblastoma. J Clin Oncol, 25(4), 376-383.

Ribatti, D., Nico, B., Pezzolo, A., Vacca, A., Meazza, R., Cinti, R., et al. (2006). Angiogenesis in a human neuroblastoma xenograft model: mechanisms and inhibition by tumorderived interferon-gamma. Br J Cancer, 94(12), 1845-1852.

Hendrix, M. J. , Seffor, R.E., Seftor, E.A., Gruman, L.M., Lee, L.M., Nickoloff, B.J., et al. (2002).Transendothelial function of human metastatic melanoma cells: role of the microenvironment in cell-fate determination. Cancer Res, 62(3), 665-668.

Bruno, S., Bussolati, B., Grange, C., Collino, F., Graziano, M.E., Ferrando, U., et al. (2006). CD133+ renal progenitor cells contribute to tumor angiogenesis. Am J Pathol, 169(6), 2223-2235.

Kusumbe, A.P., Mali, A.M., \& Bapat, S.A. (2009). CD133 expressing stem cells associated with ovarian metastases establish an endothelial hierarchy and contribute to tumor vasculature. Stem cells, 27(3), 498-508.

Shen, R., Ye, Y., Chen, L., Yan, Q., Barsky, S.H., \& Gao, J.X. (2008). Precancerous stem cells can serve as tumor vasculogenic progenitors. PLoS One, 3(2), e1652.

Chen, L., Shen, R., Ye, Y., Pu, X.A., Liu, X., Duan, W., et al. (2007). Precancerous stem cells have the potential for both benign and malignant differentiation. PLoS One, 2(3), e293.

Bussolati, B., Grange, C., Sapino, A., Camussi, G. (2009). Endothelial cell differentiation of human breast tumor stem/progenitor cells. J Cell Mol Med, 13(2), 309-319. 
Bussolati, B., Bruno, S., Gristina, G., Ferrando, U., \& Camussi, G. Identification of a tumorinitiating stem cell population in human renal carcinomas. (2008). FASEB J, 22(10), 3696-3705.

Alvero, A.B., Fu, H.H., Holmberg, J., Visintin, I., Mor, L., Marquina, C.C., et al. (2009). Stemlike ovarian cancer cells can serve as tumor vascular progenitors. Stem Cells, 27(10), 2405-2413.

Dorsam RT, Gutkind JS. G-protein-coupled receptors and cancer. Nat Rev Cancer., 2007; 7: 79-94.

Folberg R, Maniotis AJ. Vasculogenic mimicry. APMIS., 2004; 12(7-8): 508-525.

Hendrix MJ, Seftor EA, Hess AR, Seftor RE. Vasculogenic mimicry and tumour-cell plasticity: lessons from melanoma. Nat Rev Cancer,, 2003; 3:411-421.

Sun B, Zhang S, Zhao X, Zhang W, Hao X. Vasculogenic mimicry is associated with poor survival in patients with mesothelial sarcomas and alveolar rhabdomyosarcomas. Int J Oncol., 2004; 25:1609-1614.

Van Der Schaft DW, Seftor RE, Seftor EA, Hess AR, Gruman LM, Kirschmann DA, Yokoyama Y, Griffioen AW, Hendrix MJ. Effects of angiogenesis inhibitors on vascular network formation by human endothelial and melanoma cells. J Natl Cancer Inst., 2004; 96:1473-1477.

Folkman, J. Angiogenesis: an organizing principle for drug discovery? Nat Rev Drug Discov., 2007; 6(4): 273-286.

Gao JX. Cancer stem cells: the lessons from precancerous stem cells. J Cell Mol Med., 2007; 58: 267-284.

PezzoloA, Parodi F, Corrias MV, Cinti R, Gambini C, Pistoia V. Tumor origin of endothelial cells in human neuroblastoma. J Clin Oncol., 2007; 25(4): 376-383.

Shen R, Ye Y, Chen L, Yan QT, Barsky SH, Gao JX. Precancerous stem cells can serve as tumor vasculogenic progenitors. PLoS ONE, 2008; 3(2): e1652.

Bjerkvig R, Tysnes BB, Aboody KS, Najbauer J, Terzis AJA. The origin of the cancer stem cell: current controversies and new insights. Nat Rev Cancer., 2005; 5:899-904.

Maniotis AJ, Folberg R, Hess A, Seftor EA, Gardner LMG, Pe'er J, Trent JM, Meltzer PS, Hendrix MJC. Vascular channel formation by human melanoma cells in vivo and in vitro: vasculogenic mimicry. Am J Pathol., 1999; 155: 739-752.

Hendrix MJ, Seftor EA, Meltzer PS, Gardner LM, Hess AR, Kirschmann DA, Schatteman GC, Seftor RE. Expression and functional significance of VE-cadherin in aggressive human melanoma cells: role in vasculogenic mimicry. Proc Natl Acad Sci USA., 2001; 98(14): 8018-8023.

Frenkel S, Barzel I, Levy J, Lin AY, Bartsch DU, Majumdar D, Folberg R, Pe'er J. Demonstrating circulation in vasculogenic mimicry patterns of uveal melanoma by confocal indocyanine green angiography. Eye, 2008; 22(7): 948-952.

Zhang S, Guo H, Zhang D, Zhang W, Zhao X, Ren Z, Sun B. Microcirculation patterns in different stages of melanoma growth. Ocol Rep., 2006; 15(1): 15-20.

Folberg R, Hendrix MJ, Maniotis AJ. Vasculogenic mimicry and tumor angiogenesis. Am J Pathol., 2000; 156(2):361-381.

Shirakawa K, Heike Y, Watanabe I, Yanmada S, Saito K, Konishi F. Vasculogenic mimicry and pseudo-comedo formation in breast. Int J Cancer., 2002; 99(6):812-828. 
Sun B, Zhang S, Zhao X, Zhang W, Hao X. Vasculogenic mimicry is associated with poor survival in patients with mesothelial sarcomas and alveolar rhabdomyosarcomas. Int J Oncol., 2004; 25(6):1609-1614.

Elzarrad K, Haroon A, Reed D, Al-Mehdi AB. Early incorporated endothelial cells as origin of metastatic tumor vasculogenesis. Clin Exp Metastasis., 2009; 26(6): 589-598.

Yue WY, Chen ZP. Does vasculogenic mimicry exist in astrocytoma? J Histochem Cytochem., 2005; 53(8):997-1002.

Su M, Feng YJ, Yao LQ, Cheng MJ, Xu CJ, Huang Y, Zhao YQ, Jiang H. Plasticity of ovarian cancer cell SKOV3ip and vasculogenic mimicry in vivo. Int J Gynecol Cancer., 2008; 18(3):476-486.

Schatton T, Frank MH. Cancer stem cells and human malignant melanoma. Pigment Cell Melanoma Res., 2008; 21(1):39-55.

Carmeliet P. Mechanisms of angiogenesis and arteriogenesis. Nat Med., 2000; 6(4): 389-395.

Galli R, Binda E, Orfanelli U, Cipelliti B, Gritti A, De Vitis S, Fiocco R, Foroni C, Dimeco F, Vescovi A. Isolation and characterization of tumorigenic, stem-like neural precursors from human glioblastoma. Cancer Res., 2004; 64(19):7011-7021.

Singh SK, Hawkins C, Clarke ID, Squire JA, Bayani J, Hide T, Henkelman RM, Cusimano MD, Dirks PB. Identification of human brain tumour initiating cells. Nature, 2004; 432(7015):396-401.

D'Amour KA, Gage FH. Genetic and functional differences between multipotent neural and pluripotent embryonic stem cells. Proc Natl Acad Sci USA., 2003; 100 (Suppl 1): 11866-11872.

Reya T, Duncan AW, Ailles L, Domen J, Scherer DC, Willert K, Hintz L, Nusse R, Weissman IL. A role for Wnt signalling in self-renewal of haematopoietic stem cells. Nature, 2003; 423(6938): 409-414.

Schatton T, Murphy GF, Frank NY, Yamaura K, Waaga-Gasser AM, Gasser M, Zhan Q, Jordan S, Duncan LM, Weishaupt C, Fuhlbrigge RC, Kupper TS, Sayegh MH, Frank MH. Identification of cells initiating human melanomas. Nature, 2008; 451:345-349.

Bussolati B, Grange C, Sapino A, Camussi G. Endothelial cell differentiation of human breast tumor stem/ progenitor cells. J Cell Mol Med., 2009; 13(2):309-319.

Rigolin GM, Fraulini C, Ciccone M, Mauro E, Bugli AM, De Angeli C, Negrini M, Cuneo A, Castoldi G. Neoplastic circulating endothelial cells in multiple myeloma with 13q14 deletion. Blood, 2006; 107(6):2531-2535.

Medina MA, Munoz-Ch Puli R, Quesada AR. Challenges of antiangiogneic cancer therapy: trials and errors, and renewed hope. J Cell Mol Med., 11:378-382.

Yi L, Zhou ZH, PingYF, Chen JH, Yao XH, Feng H, Lu JY, Wang JM, Bian XW. Isolation and characterization of stem cell-like precursor cells from primary human anaplastic oligoastrocytoma. Mod Pathol., 2007; 20: 1061-1068.

Yu SC, Ping YF, Yi L, Zhou ZH, Chen JH, Yao XH, Gao L, Wang JM, Bian XW. Isolation and characterization of cancer stem cells from a human glioblastoma cell line U87. Cancer Lett., 2008; 265:124-134.

Elias AP, Dias S. Microenvironment Changes (in $\mathrm{pH}$ ) Affect VEGF Alternative Splicing. Cancer Microenviron., 2008; 1(1):131-139. 
Hendrix MJ, Seftor EA, Kirschmann DA, Quaranta V, Seftor RE. Remodeling of the microenvironment by aggressive melanoma tumor cells. Ann N Y Acad Sci., 2003; 995:151-161.

Schofield R. The relationship between the spleen colony-forming cell and the haemopoietic stem cell. Blood Cells, 1978; 4:7-25.

Morrison SJ, Kimble J. Asymmetric and symmetric stem-cell division in development and cancer. Nature, 2006; 441:1068-1074.

Scadden DT. The stem cell niche as an entity of action. Nature, 2006; 41:1075-1079.

Vermeulen L, Todaro M, de Sousa Mello F, Sprick MR, Kemper K, Perez Alea M, Richel DJ, Stassi G, Medema JP. Single-cell cloning of colon cancer stem cells reveals a multilineage differentiation capacity. Proc Natl Acad Sci USA., 2008; 105(36):1342713432.

Calabrese C, Poppleton H, Kocak M, Hogg TL, Fuller C, Hamner B, Oh EY, Gaber MW, Finklestein D, Allen M, Frank A, Bayazitov IT, Zakharenko SS, Gajjar A, Davidoff A, Gilbertson RJ. A perivascular niche for brain tumor stem cells. Cancer Cell, 2007; 11(1):69-82.

Rothhammer T, Bataille F, Spruss T, Eissner G, Bosserhoff AK. Functional implication of BMP4 expression on angiogenesis in malignant melanoma. Oncogene, 2007; 26:4158-4170.

Piccirillo SG, Reynolds BA, Zanetti N, Lamorte G, Binda E, Broggi G, Brem H, Olivi A, Dimeco F, Vescovi AL. Bone morphogenetic proteins inhibit the tumorigenic potential of human brain tumour-initiating cells. Nature, 2006; 444:761-765.

Nakano I, Saigusa K, Kornblum HI. BMPing off glioma stem cells. Cancer Cell, 2008; 13(1):3-4.

Yao XH, Ping YF, Chen JH, Xu CP, Chen DL, Zhang R, Bian XW. Glioblastoma stem cells produce vascular endothelial growth factor by activation of formylpeptide receptor (FPR). J Pathol., 2008; 215(4): 369-376.

Basu GD, Liang WS, Stephan DA, Wegener LT, Conley CR, Pockaj RA, Mukherjee P. A novel role for cyclooxygenase- 2 in regulating vascular channel formation by human breast cancer cells. Breast Cancer Res., 2006; 8(6): R69.

Fujimoto AOH, Mori A, Nagayama S, Yonenaga Y, Tachibana T. Tumor plasticity and extravascular circulation in ECV304 human bladder carcinoma cells. Anticancer Res., 2006; 26(1A): 59-69.

Stevens AP, Spangler B, Wallner S, Kreutz M, Dettmer K, Oefner PJ, Bosserhoff AK. Direct and tumor microenvironment mediated influences of 5'-deoxy-5'-(methylthio) adenosine on tumor progression of malignant melanoma. J Cell Biochem., 2009; 106(2):210-219.

Yu SC, Bian XW. Enrichment of cancer stem cells based on heterogeneity of invasiveness. Stem Cell Rev., 2009, 5(1): 66-71.

Hess AR, Seftor EA, Seftor RE, Hendrix MJ. Phosphoinositide 3-kinase regulates membrane Type 1-matrix metalloproteinase (MMP) and MMP-2 activity during melanoma cell vasculogenic mimicry. Cancer Res., 2003; 63(16):4757-4762.

Hillen F, Griffoen AW. Tumour vascularization: sprouting angiogenesis and beyond. Cancer Metastasis Rev., 2007; 26:489-502. 
Borovski, T., Verhoeff, J.J., ten Cate, R., Cameron, K., de Vries, N.A., van Tellingen, O., et al. (2009).Tumor microvasculature supports proliferation and expansion of gliomapropagating cells. Int J Cancer, 125(5), 1222-1230.

Rak, J., Milsom, C., \& Yu, J. (2008). Vascular determinants of cancer stem cell dormancy-do age and coagulation system play a role? APMIS, 116(7-8), 660-676.

Priceman, S.J., Sung, J.L., Shaposhnik, Z., Burton, J.B., Torres-Collado, A.X., Moughon, D.L., et al. (2010). Targeting distinct tumor-infiltrating myeloid cells by inhibiting CSF-1 receptor: combating tumor evasion of antiangiogenic therapy. Boold, 115(7), 14611471.

Koukourakis, M.I., Giatromanolaki, A., Sheldon, H., Buffa, F.M., Kouklakis, G., Ragoussis, I., et al. (2009). Phase I/II trial of bevacizumab and radiotherapy for locally advanced inoperable colorectal cancer: vasculature-independent radiosensitizing effect of bevacizumab. Clin Cancer Res, 15(22), 7069-7076.

Ito, K., Bernardi, R., Morotti, A., Matsuoka, S., Saglio, G., Ikeda, Y., et al. (2008). PML targeting eradicates quiescent leukaemia-initiating cells. Nature, 453(7198), 10721078. 


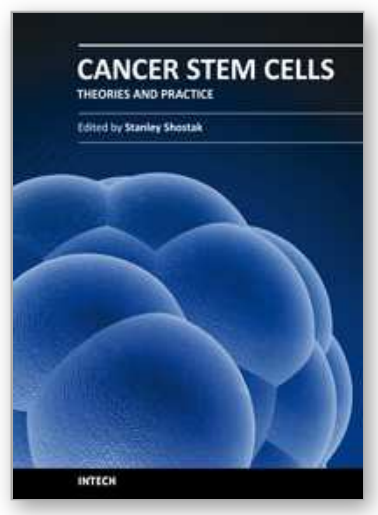

\author{
Cancer Stem Cells Theories and Practice \\ Edited by Prof. Stanley Shostak
}

ISBN 978-953-307-225-8

Hard cover, 442 pages

Publisher InTech

Published online 22, March, 2011

Published in print edition March, 2011

Cancer Stem Cells Theories and Practice does not 'boldly go where no one has gone before!' Rather, Cancer Stem Cells Theories and Practice boldly goes where the cutting edge of research theory meets the concrete challenges of clinical practice. Cancer Stem Cells Theories and Practice is firmly grounded in the latest results on cancer stem cells (CSCs) from world-class cancer research laboratories, but its twenty-two chapters also tease apart cancer's vulnerabilities and identify opportunities for early detection, targeted therapy, and reducing remission and resistance.

\title{
How to reference
}

In order to correctly reference this scholarly work, feel free to copy and paste the following:

Yi-fang Ping, Xiao-hong Yao, Shi-cang Yu, Ji Ming Wang and Xiu-wu Bian (2011). Cancer Stem Cells Promote Tumor Neovascularization, Cancer Stem Cells Theories and Practice, Prof. Stanley Shostak (Ed.), ISBN: 978953-307-225-8, InTech, Available from: http://www.intechopen.com/books/cancer-stem-cells-theories-andpractice/cancer-stem-cells-promote-tumor-neovascularization

\section{INTECH}

open science | open minds

\section{InTech Europe}

University Campus STeP Ri

Slavka Krautzeka 83/A

51000 Rijeka, Croatia

Phone: +385 (51) 770447

Fax: +385 (51) 686166

www.intechopen.com

\section{InTech China}

Unit 405, Office Block, Hotel Equatorial Shanghai

No.65, Yan An Road (West), Shanghai, 200040, China

中国上海市延安西路65号上海国际贵都大饭店办公楼 405 单元

Phone: +86-21-62489820

Fax: +86-21-62489821 
(C) 2011 The Author(s). Licensee IntechOpen. This chapter is distributed under the terms of the Creative Commons Attribution-NonCommercialShareAlike-3.0 License, which permits use, distribution and reproduction for non-commercial purposes, provided the original is properly cited and derivative works building on this content are distributed under the same license. 